\title{
Relationship Between Marital Satisfaction With Maternal- infant Attachment and Breastfeeding Self-efficacy in Primiparous and Multiparous Nursing Mothers
}

\author{
Nadia Jasemi ${ }^{1}$, Parvaneh Mousavi $^{2}$, Amal Saki $^{3}$, Nahid Javadifar ${ }^{2 *}$
}

\begin{abstract}
Objectives: Parental attachment is effective on parents' feelings of commitment toward infant care and increases maternal efficiency. Given that the parity is considered as the main factor and moderator of the mother-infant interaction, the present study aimed to investigate the relationship between marital satisfaction with mother-infant attachment and breastfeeding self-efficacy and its comparison in primiparous and multiparous women.

Materials and Methods: This descriptive-correlational study was carried out using a random sampling method. A total of 420 mothers having 4-6 months children were randomly selected from health centers in Ahvaz and enrolled in the study. The required data were collected using a demographic questionnaire, ENRICH marital satisfaction scale, Müller's mother-infant attachment inventory, and Denis's breastfeeding self-efficacy questionnaire. Statistical analysis was performed using SPSS, version 20.

Results: The findings revealed that the mean scores of marital satisfaction, mother-infant attachment, and breastfeeding self-efficacy was $136.57 \pm 19.76,100.82 \pm 4.604$, and $13.148 \pm 135.75$ in primiparous women and the values of the same variables were $127.65 \pm 18.67$, $9 \pm 95.31$, and $138.66 \pm 13.889$ in multiparous women, respectively. In addition, the Pearson correlation test showed that marital satisfaction was significantly correlated with mother-infant attachment in two groups of primiparous and multiparous mothers, as well as breastfeeding self-efficacy in multiparous mothers $(P<0.05)$.

Conclusions: In general, multiparous mothers are often neglected since most of the training and counseling services provided during the perinatal period focus on new mothers. Thus, this research supports the need for educating and informing parents regarding the importance of spousal support and its effect on improving family functions.

Keywords: Marital Satisfaction, Maternal-child Attachment, Breastfeeding Self-efficacy, Parity
\end{abstract}

\section{Introduction}

Marital satisfaction is defined as meeting the expectations among partners (1), and the birth of a child can create a sense of fulfillment in the family and a new sense of life. In addition, parental attachment is effective on the parent's feeling of commitment toward infant care and increases maternal efficiency (2). Further, dissatisfaction with marital relations can lead to depression, parental stress, and a reduction in their performance as parents (3), as well as having adverse effects on children's sense of security and their social performance in the future $(4,5)$.

Breastfeeding is one of the most important factors affecting the deepening of the maternal-infant attachment, and lower breastfeeding can reduce maternal bondingrelated behaviors (6). Since breastfeeding has a dyadic nature, mothers who have more support from their spouses after giving birth and more marital satisfaction, have a greater breastfeeding self-efficacy and more likely to start and carry on breastfeeding (7).

The breastfeeding self-efficacy involves the person's belief in her ability to practice breastfeeding and requires the presence of mother-infant interactions (8). The factors affecting breastfeeding and maternal duties are mainly divided into three categories including maternal, child-related, and environmental factors such as marital satisfaction, family functioning, and socio-cultural contexts (9).

Parity is considered as a major factor moderating the mother-infant interaction among the factors affecting the family system, which can describe the effect of different family systems on infant development (10). Although it is believed that experienced mothers need fewer psychosocial interventions to promote maternal role adaptation and effective child care, the birth of the second and the next children is a stressful experience and can lead to increasing role strains and affect the quality of the mother-spouse relationship and infant care (11). Considering that previous related studies mainly focused on primiparous women, this study sought to investigate the relationship between marital satisfaction with motherinfant attachment and breastfeeding self-efficacy in primiparous and multiparous nursing mothers. 


\section{Materials and Methods}

The present cross-sectional, correlational study was approved by the Ethical Committee of Ahvaz Jundishapur University of Medical Sciences (IR.AJUMS.REC.1396.122) and conducted from October 2017 to March 2018. In this study, Ahvaz, as the capital of Khuzestan province in southern Iran was divided into 2 areas of the east with 12 health centers and west with 11 health centers and three health centers were randomly selected from each district. At each center, a list of families with a child aged 4-6 months was prepared and the sample size was randomly selected among the household records depending on the population covered by the center. Families were invited via telephone calls to attend the health care center at the same time for infant growth monitoring or vaccination and respond to questionnaires after meeting the inclusion criteria and obtaining their consent, along with ensuring the confidentiality of information. In this study, the findings of a pilot study on 60 mothers were entered the formula for comparing the means with a power of $80 \%$ and a confidence level of $95 \%$. Accordingly, the sample size of 398 was obtained, which was finally determined as 440 individuals so that to increase the validity of the data. Eventually, 20 subjects refused to take part and 420 mothers participated in the study and were divided into primiparous (first-time mothers) and multiparous (mothers with more than one child) groups. The inclusion criteria were the maternal age of over 18 years, the presence of a healthy child aged 4-6 months, the absence of maternal breast problems, term pregnancy, birth weight of over 2500 (g), and exclusive or predominant breastfeeding. On the other hand, the exclusion criteria included the presence or history of severe stress and depression during the recent years (e.g., the death of one of the first-degree family members, the serious disease of the mother or spouse, the decision for separation, and family tension). In addition, parental addiction to drug and stimulants, the history of psychiatric disorders over the past year (e.g., a history of visiting the physician, drug use, and hospitalization), infant's disease, mother-infant separation shortly after birth, and the use of infant formula were the other exclusion criteria. The data gathering tools included a demographic questionnaire which was evaluated and approved by 10 faculty members of the Ahvaz Nursing and Midwifery School. Another questionnaire was the 35-item of Enrich Marital Satisfaction Scale, which contained four subscales of marital satisfaction, communications, conflict resolution, and idealistic distortion. The final subscale measures the couples' tendency to answer questions based on acceptable social behaviors and high scores indicate a non-realistic relationship about a marital relationship. Based on the report by Asoudeh et al, the alpha coefficient of the subscales of the questionnaire was obtained 0.68 , $0.78,0.62$, and 0.77 , respectively (12).

Further, the Mother-infant Attachment Inventory by Müller consisted of 26 items and its scores ranged from
26 to 104 (13). Jafarnejad et al confirmed the validity and reliability of this questionnaire in Iran with the Cronbach's alpha coefficient of 0.89 (14). The Breastfeeding SelfEfficacy Scale includes 33 items and its scores range was 33 to 165 . This questionnaire was designed by Dennis and Faux based on Bandura's social cognitive theory (15) and Varaei et al reported the validity of $82 \%$ in Iran (16).

The normality of data was examined, followed by using the Pearson correlation test and independent t-test to determine the relationship between marital satisfaction, mother-infant attachment, and breastfeeding self-efficacy in primiparous and multiparous women. In this study, $P<0.05$ was considered as a significant level.

\section{Results}

In the present study, 280 (66.6\%) mothers had more than one child and their mean age was $28.1 \pm 4.3$ and the mean age of first-time mothers was $24.3 \pm 3.2$ years old as well. Furthermore, the mean number of children for multiparous mothers was $3.26 \pm 1.2$ and there was no statically significant difference between the two groups in terms of demographic characteristics, the details of which are provided in Table 1 . Based on the data in

\begin{tabular}{|c|c|}
\hline Variable & \\
\hline Age of mother $(y)$, (Mean \pm SD) & $26.7 \pm 5.02$ \\
\hline Age of spouse $(y)$, (Mean $\pm S D$ ) & $30.6 \pm 4.7$ \\
\hline Age of marriage (mother), (Mean \pm SD) & $20.6 \pm 3.3$ \\
\hline Number of children, (Mean \pm SD) & $1.8 \pm .9$ \\
\hline Age of infant (mon), (Mean \pm SD) & $4.8 \pm .8$ \\
\hline \multicolumn{2}{|l|}{ Sex of infant, No. (\%) } \\
\hline Male & $48.6 \%(204)$ \\
\hline Female & $51.4 \%(216)$ \\
\hline \multicolumn{2}{|l|}{ Education of mother, No. (\%) } \\
\hline Middle school & $35.7 \%(150)$ \\
\hline High school & $18.8 \%(79)$ \\
\hline Diploma & $29.5 \%(124)$ \\
\hline University & $16 \%(67)$ \\
\hline \multicolumn{2}{|l|}{ Education of spouse, No. (\%) } \\
\hline Illiterate & $1.9 \%(8)$ \\
\hline Primary school & $8.3 \%(35)$ \\
\hline Middle school & $21.75(91)$ \\
\hline High school & $13.3 \%(56)$ \\
\hline Diploma & $36.9 \%(155)$ \\
\hline University & $17.9 \%(75)$ \\
\hline \multicolumn{2}{|l|}{ Job of mother, No. (\%) } \\
\hline House wife & $94.5 \%(397)$ \\
\hline Working & $5.55(23)$ \\
\hline \multicolumn{2}{|l|}{ Job of spouse } \\
\hline Employed & $92.9 \%(390)$ \\
\hline Unemployed & $7.1 \%(30)$ \\
\hline \multicolumn{2}{|l|}{ Living status } \\
\hline Living with husband family & $62.1 \%(261)$ \\
\hline Independent & $37.9 \%(159)$ \\
\hline \multicolumn{2}{|l|}{ Family income } \\
\hline Insufficient & $58.5 \%(246)$ \\
\hline Sufficient & $41.5 \%(174)$ \\
\hline
\end{tabular}


Table 2, marital satisfaction in multiparous women was significantly lower than primiparous women $(P<0.05)$. According to the findings of Table 3, the Pearson correlation test demonstrated a significant relationship between marital satisfaction and all its domains with mother-infant attachment $(P<0.001)$ while there was no significant correlation between conflict resolution subscale and general marital satisfaction score with breastfeeding self-efficacy $(P>0.05)$. The results (Table 4$)$ revealed that the mean mother-infant attachment score in primiparous women was higher compared to multiparous mothers. Moreover, the average breastfeeding self-efficacy score in multiparous women was more than primiparous mothers and these differences were statistically significant $(P<0.05)$. Additionally, the results of Pearson correlation test (Table 5) indicated that marital satisfaction had a significant relationship with mother-infant attachment in both primiparous and multiparous mothers and

Table 2. Marital Satisfaction and its Domains in Primiparous and Multiparous Mothers

\begin{tabular}{lccc}
\hline & $\begin{array}{c}\text { Primiparous } \\
\text { (Mean } \pm \text { SD) }\end{array}$ & $\begin{array}{c}\text { Multiparous } \\
\text { (Mean } \pm \text { SD) }\end{array}$ & P value \\
\hline Marital satisfaction & $41.46 \pm 5.33$ & $39.20 \pm 5.75$ & $<0.001$ \\
Communications & $38.56 \pm 6.01$ & $35.61 \pm 6.69$ & $<0.001$ \\
Conflict resolution & $36.11 \pm 7.16$ & $32.76 \pm 6.94$ & $<0.001$ \\
Idealistic distortion & $20.79 \pm 3.05$ & $19.60 \pm 2.80$ & $<0.001$ \\
Total & $136 \pm 19.76$ & $127.65 \pm 1867$ & $<0.001$ \\
\hline
\end{tabular}

Table 3. Relation Between Marital Satisfaction and its Domains With Mother-Infant Attachment and Breast Feeding Self-efficacy

\begin{tabular}{lcccc}
\hline & \multicolumn{2}{c}{$\begin{array}{c}\text { Mother-infant } \\
\text { Attachment }\end{array}$} & \multicolumn{2}{c}{$\begin{array}{c}\text { Breastfeeding Self- } \\
\text { efficacy }\end{array}$} \\
\cline { 2 - 5 } & Correlation & $\boldsymbol{P}$ value & Correlation & $\boldsymbol{P}$ value \\
\hline Marital satisfaction & 0.368 & $<0.001$ & 0.126 & 0.01 \\
Communications & 0.333 & $<0.001$ & 0.151 & 0.002 \\
Conflict resolution & 0.272 & $<0.001$ & 0.967 & 0.17 \\
Idealistic distortion & 0.348 & $<0.001$ & 0.157 & 0.001 \\
Total & 0.268 & $<0.001$ & 0.031 & 0.35 \\
\hline
\end{tabular}

Table 4. Mother-Infant Attachment and Breast Feeding Self-efficacy

\begin{tabular}{llll}
\hline & $\begin{array}{l}\text { Primiparous } \\
\text { (Mean } \pm \text { SD) }\end{array}$ & $\begin{array}{l}\text { Multiparous } \\
\text { (Mean } \pm \text { SD) }\end{array}$ & P-value \\
\hline Mother-infant attachment & $100.82 \pm 4.60$ & $95.31 \pm 9.09$ & $<0.001$ \\
Breast feeding self efficacy & $135.75 \pm 13.15$ & $138.66 \pm 13.89$ & 0.04 \\
\hline
\end{tabular}

breastfeeding self-efficacy in multiparous mothers as well $(P<0.05)$. However, no significant relationship was observed between breastfeeding self-efficacy and marital satisfaction in primiparous women $(P>0.05)$.

\section{Discussion}

Previous studies carried out in Iran reported a very different marital satisfaction rate among Iranian women ranging from very high to low levels. This is due to differences in the sampling method, target population, or instruments (17-19). In this study, the mean marital satisfaction score represented good marital satisfaction of mothers who participated in this study.

However, the score of the mean marital satisfaction and all its subscales were lower in multiparous mothers compared to nulliparous women $(P<0.001)$. The findings of this study are consistent with the views of some researchers who believed that the birth of a second child can increase the maternal focus on the child while reducing the relationship between mother and spouse and thus increasing the marriage strain $(20,21)$. Nichols et al argued that multiparous women receive less spousal support and show less attachment to the newborn baby compared to primiparous mothers. However, the main concerns of primiparous women were family financial affairs and the changes which occurred in postpartum marital relationships (11). Fish and Stifter also reported that multiparous mothers have more self-efficacy and first-time mothers suffer from postpartum marital ambivalence more frequently than multiparous mothers (10).

In this study, the mean score of mother-infant attachment was in a very good range [30-32]. In addition, marital satisfaction and its subscales were significantly correlated with mother-infant attachment and, consistent with other studies, confirmed the mutual relationship between marital satisfaction and the mother-infant attachment $(22,23)$.

Similarly, both groups of primiparous and multiparous mothers had a very good mean attachment score in the present study. The results of this study are in line with the findings of other studies showing that multiparous mothers have less attachment to infants despite their higher ability for understanding maternal-infant cue perception compared to primiparous mothers $(24,25)$, which contradicts the findings of several other studies $(26,27)$.

Table 5. Relation Between Marital Satisfaction With Mother-infant Attachment and Breast Feeding Self-efficacy in Primiparous and Multiparous Mothers

\begin{tabular}{lcccc}
\hline & Marital Satisfaction With Mother-infant Attachment & \multicolumn{2}{c}{ Marital Satisfaction With Breast Feeding Self-efficacy } \\
\cline { 2 - 5 } & Correlation & $\boldsymbol{P}$ Value & Correlation & \multicolumn{1}{c}{$\boldsymbol{P}$ Value } \\
\hline Primiparous & 0.221 & 0.009 & 0.076 & 0.37 \\
Multiparous & 0.355 & 0.05 & 0.191 & 0.001 \\
Total & 0.357 & $<0.001$ & 0.126 & 0.01 \\
\hline
\end{tabular}


The mean score of breastfeeding self-efficacy of the participants was in a very good range (within the range of 33-165) and is in line with the results of previous studies (28-30). In this research, although there was a significant relationship between the subscales of satisfaction, communication, and idealistic distortion with breastfeeding self-efficacy, no significant relationship was found between the total marital satisfaction score and the conflict resolution subscale. Some studies revealed that higher marital satisfaction and supportive role of fathers is a highly important factor in starting and continuing breastfeeding until the end of the first year of the infant's life $(31,32)$. Thus, "family-centered breastfeeding triad" approach, which emphasizes the importance of the paternal role in this regard, has replaced the traditional concept of "breastfeeding dyad" which is limited to the role of infant and mother in breastfeeding (33). Bandura believes that having a breastfeeding experience is one of the contributing factors to breastfeeding self-efficacy, which corroborates with the results of the present study (34). Studies have also shown that multiparous women are more likely to start breastfeeding and continue it for prolonged periods compared to primiparous women $(35,36)$ while Dodt et al did not find such a relationship (37).

In this study, there was no significant relationship between marital satisfaction and breastfeeding selfefficacy in primiparous women. This means that breastfeeding self-efficacy is not affected by marital satisfaction in primiparous women contrary to multiparous women. Although no study has focused on investigating the relationship between marital satisfaction with breastfeeding self-efficacy in these two groups, marital satisfaction seems to play a moderating role since multiparous mothers experience tension and role strains more compared to primiparous mothers. Thus, marital satisfaction is related to breastfeeding self-efficacy in multiparous mothers.

\section{Limitations of the Study}

In the present study, the sampling was carried out on mothers who either practiced exclusive breastfeeding or a major part of their child's feeding was based on breastfeeding. Therefore, mothers of formula-fed children were not studied and this limits the generalizability of the results of this study to all primiparous and multiparous women. Another limitation of this research is its crosssectional nature, therefore, the confirmed relationships in this research do not necessarily indicate a causal relation. Another limitation was the fact that fathers did not participate in the present study and that this research was not a longitudinal study. Thus, further studies are suggested in this regard in the future. However, the strong points of this research include using random sampling, as well as valid and reliable instruments.

\section{Conclusions}

The results of this study indicate that multiparous women had less marital satisfaction and showed less attachment to their children despite the good total mean of marital satisfaction scores, mother-infant attachment, and the breastfeeding self-efficacy of all participated nursing mothers. The results also revealed that a higher marital satisfaction rate increases the mother-infant attachment in both groups of mothers.

Based on the results, no significant relationship was observed between breastfeeding self-efficacy and marital satisfaction in primiparous mothers, but breastfeeding selfefficacy could affect marital satisfaction in multiparous mothers.

It should be noted that many multiparous mothers are often neglected since most of the training and counseling presented during pregnancy and postpartum focus on new mothers. Therefore, the results of this research support the need for training and counseling the parents, especially fathers about the importance of spousal support and its effect on improving family functions, as well as encouraging the couples to establish the frequency and enhancing the quality of relationships.

\section{Conflict of Interests}

Authors declare that they have no conflict of interests.

\section{Financial Support}

This research article was extracted from a master's thesis (No: B-9688. IR.AJUMS.REC.1396.122) and financial support was provided by Ahvaz Jundishapur University of Medical Sciences.

\section{References}

1. Carlson J, Sperry L. Recovering intimacy in love relationships: a clinician's guide. New York: Routledge; 2010.

2. Kwan RWH, Kwok SYCL, Ling CCY. The moderating roles of parenting self-efficacy and co-parenting alliance on marital satisfaction among Chinese fathers and mothers. J Child Fam Stud. 2015;24(12):3506-3515. doi:10.1007/s10826-015-0152-4

3. Kersh J, Hedvat TT, Hauser-Cram P, Warfield ME. The contribution of marital quality to the well-being of parents of children with developmental disabilities. J Intellect Disabil Res. 2006;50(Pt 12):883-893. doi:10.1111/j.13652788.2006.00906.x

4. Lickenbrock DM, Braungart-Rieker JM. Examining antecedents of infant attachment security with mothers and fathers: an ecological systems perspective. Infant Behav Dev. 2015;39:173-187. doi:10.1016/j.infbeh.2015.03.003

5. Houlston C. Marital conflict and children: an emotional security perspective. Edited by E. Mark Cummings and Patrick T. Davies. Guilford Press, New York, 2010. pp. 320. Price: $£ 27$, US\$40. ISBN: 978-1606235195. Infant Child Dev. 2011;20(4):446-447. doi:10.1002/icd.722

6. Schwarze CE, Hellhammer DH, Stroehle V, Lieb K, Mobascher A. Lack of breastfeeding: a potential risk factor in the multifactorial genesis of borderline personality disorder and impaired maternal bonding. J Pers Disord. 2015;29(5):610626. doi:10.1521/pedi_2014_28_160

7. Isabella $\mathrm{PH}$, Isabella RA. Correlates of successful 
breastfeeding: a study of social and personal factors. J Hum Lact. 1994;10(4):257-264. doi:10.1177/089033449401000421

8. Noel-Weiss J, Rupp A, Cragg B, Bassett V, Woodend AK. Randomized controlled trial to determine effects of prenatal breastfeeding workshop on maternal breastfeeding self-efficacy and breastfeeding duration. J Obstet Gynecol Neonatal Nurs. 2006;35(5):616-624. doi:10.1111/j.1552-6909.2006.00077.x

9. Shorey S, Chan SW, Chong YS, He HG. Predictors of maternal parental self-efficacy among primiparas in the early postnatal period. West J Nurs Res. 2015;37(12):1604-1622. doi:10.1177/0193945914537724

10. Fish M, Stifter CA. Mother parity as a main and moderating influence on early mother-infant interaction. J Appl Dev Psychol. 1993;14(4):557-572. doi:10.1016/01933973(93)90007-I

11. Nichols MR, Roux GM, Harris NR. Primigravid and multigravid women: prenatal perspectives. J Perinat Educ. 2007;16(2):21-32. doi:10.1624/105812407x192019

12. Asoodeh MH, Khalili S, Daneshpour M, Lavasani MG. Factors of successful marriage: accounts from self described happy couples. Procedia Soc Behav Sci. 2010;5:2042-2046. doi:10.1016/j.sbspro.2010.07.410

13. Müller ME. A questionnaire to measure mother-toinfant attachment. J Nurs Meas. 1994;2(2):129-141. doi:10.1891/1061-3749.2.2.129

14. Jafarnezhad F, Moghadam Hosseini V, Soltanifar A, Ebrahimzadeh S. Study of the relationship between domestic violence intensity during pregnancy and mother-infant attachment. Journal of Sabzevar University of Medical Sciences. 2009;16(1):35-42. [Persian].

15. Dennis CL, Faux S. Development and psychometric testing of the Breastfeeding Self-Efficacy Scale. Res Nurs Health. 1999;22(5):399-409. doi:10.1002/(sici) 1098240x(199910)22:5<399::aid-nur6>3.0.co;2-4

16. Varaei S, Mehrdad N, Bahrani N. The Relationship between Self-efficacy and Breastfeeding, Tehran, Iran. Hayat. 2009;15(3):31-38. [Persian].

17. Rahmani A, Merghati Khoei E, Alah Gholi L. Sexual satisfaction and its relation to marital happiness in Iranians. Iran J Public Health. 2009;38(4):77-82.

18. Ghahremani F, Ahmadi Doulabi M, Eslami M, ShekarrizFoumani R. Correlation between number and gender composition of children and marital satisfaction in women presenting to health centers in Tehran-Iran, 2015. Iran J Psychiatry Behav Sci. 2017;11(2):e9598. doi:10.5812/ ijpbs. 9598

19. Ziaee T, Jannati Y, Mobasheri E, et al. The relationship between marital and sexual satisfaction among married women employees at Golestan University of Medical Sciences, Iran. Iran J Psychiatry Behav Sci. 2014;8(2):44-51.

20. Dunn J. From one child to two: what to expect, how to cope, and how to enjoy your growing family. New York: Fawcett Columbine; 1995.

21. O'Reilly MM. Achieving a new balance: women's transition to second-time parenthood. J Obstet Gynecol Neonatal Nurs. 2004;33(4):455-462. doi:10.1177/0884217504266911

22. van Ijzendoorn MH, Schuengel C, Bakermans-Kranenburg MJ. Disorganized attachment in early childhood: meta-analysis of precursors, concomitants, and sequelae. Dev Psychopathol.
1999;11(2):225-249. doi:10.1017/s0954579499002035

23. Ding YH, Xu X, Wang ZY, Li HR, Wang WP. Study of mother-infant attachment patterns and influence factors in Shanghai. Early Hum Dev. 2012;88(5):295-300. doi:10.1016/j. earlhumdev.2011.08.023

24. van Bussel JC, Spitz B, Demyttenaere K. Reliability and validity of the Dutch version of the maternal antenatal attachment scale. Arch Womens Ment Health. 2010;13(3):267-277. doi:10.1007/s00737-009-0127-9

25. Maupin AN, Rutherford HJV, Landi N, Potenza MN, Mayes LC. Investigating the association between parity and the maternal neural response to infant cues. Soc Neurosci. 2019;14(2):214-225. doi:10.1080/17470919.2017.1422276

26. Cranley MS. Development of a tool for the measurement of maternal attachment during pregnancy. Nurs Res. 1981;30(5):281-284.

27. Shariat $M$, Abedinia $N$. The effect of psychological intervention on mother-infant bonding and breastfeeding. Iranian Journal of Neonatology. 2017;8(1):7-15. doi:10.22038/ ijn.2017.16673.1191

28. Otsuka K, Taguri M, Dennis CL, et al. Effectiveness of a breastfeeding self-efficacy intervention: do hospital practices make a difference? Matern Child Health J. 2014;18(1):296-306. doi:10.1007/s10995-013-1265-2

29. Maleki- Saghooni N, Amel Barez M, Moeindarbari S, Karimi FZ. Investigating the Breastfeeding Self-Efficacy and its Related Factors in Primiparous Breastfeeding Mothers. Int J Pediatr. 2017;5(12):6275-6283. doi:10.22038/ijp.2017.25656.2182

30. Pakseresht S, Pourshaban F, Khalesi ZB. Comparing maternal breastfeeding self-efficacy during first week and sixth week postpartum. Electron Physician. 2017;9(2):3751-3755. doi:10.19082/3751

31. Rempel LA, Rempel JK. The breastfeeding team: the role of involved fathers in the breastfeeding family. J Hum Lact. 2011;27(2):115-121. doi:10.1177/0890334410390045

32. Isabella RA, Belsky J. Marital change during the transition to parenthood and security of infant-parent attachment. J Fam Issues. 1985;6(4):505-522. doi:10.1177/019251385006004006

33. Mitchell-Box K, Braun KL. Fathers' thoughts on breastfeeding and implications for a theory-based intervention. J Obstet Gynecol Neonatal Nurs. 2012;41(6):E41-50. doi:10.1111/ j.1552-6909.2012.01399.x

34. Bandura A. Self-efficacy: toward a unifying theory of behavioral change. Adv Behav Res Ther. 1978;1(4):139-161. doi:10.1016/0146-6402(78)90002-4

35. Simard I, O’Brien HT, Beaudoin A, et al. Factors influencing the initiation and duration of breastfeeding among lowincome women followed by the Canada prenatal nutrition program in 4 regions of quebec. J Hum Lact. 2005;21(3):327337. doi:10.1177/0890334405275831

36. Bourgoin GL, Lahaie NR, Rheaume BA, et al. Factors influencing the duration of breastfeeding in the Sudbury region. Can J Public Health. 1997;88(4):238-241. doi:10.17269/ cjph.88.923

37. Dodt RCM, Ximenes LB, Almeida PC, Oriá MOB, Dennis CL. Psychometric and maternal sociodemographic assessment of the breastfeeding self-efficacy scale - short form in a Brazilian sample. J Nurs Educ Pract. 2012;2(3):66-73. doi:10.5430/jnep. v2n3p66

(c) 2020 The Author (s); This is an open-access article distributed under the terms of the Creative Commons Attribution License (http://creativecommons.org/licenses/by/4.0), which permits unrestricted use, distribution, and reproduction in any medium, provided the original work is properly cited. 